\title{
The role of health education in childhood injury prevention
}

\author{
EML Towner
}

In the debate about the relative merits of different preventive strategies in injury prevention, environmental changes, and legislation are often regarded as superior and more effective approaches to those involving health education. Stone, for example, has suggested that an inverse proportion law operates, with preventive activities receiving official support in inverse proportion to their effectiveness. 'socio-environmental change is costly, radical and unpredictable and is consequently unattractive to politicians, in contrast to health education which is, 'cheap, generally uncontroversial and safe'. ${ }^{1}$ Roberts et al support this viewpoint: 'It is unclear what part, if any, educational health promotion messages have played in the reduction of accidents', ${ }^{2}$ as does Sibert: 'The evidence that these [educational campaigns] are effective is unconvincing' and in most cases, effective solutions 'involve environmental changes'. ${ }^{3}$ Within the authors' definitions of health education their comments have some validity, but what is their definition of health education? This review contends that many criticisms of health education are based on a narrow view of what it can contribute. For example, Roberts $e t$ al question whether health education is effective for parents, but later in their arguments advocate that knowledge of local lay opinion and citizens' safe keeping strategies could be fruitfully used 'to provide information and education, not only for other parents, but for decision makers in local and central government' ${ }^{2}$ Education is rejected in the first instance and advocated in the second. In supporting the superiority of environmental and legislative interventions, the wider processes of education are largely ignored.

This paper seeks to demonstrate that health education has a wider role than one solely directed at individualised behaviour change. Health education underpins both legislative and environmental measures. My goal is to set the scene by summarising different ideologies that underlie contrasting models of health education and the principles of education that facilitate effective teaching and learning. I examine the range of available strategies for different injury types, and assess whether educational programmes focused on individuals or groups can be effective in promoting safety or preventing injuries by comparing the characteristics of ineffective and effective programmes. The processes by which legislation and environmental measures are introduced are then described and issues related to education of professionals, policy makers, and the wider community are discussed.

\section{Models of health education}

Whitehead considers that health education is one component of the overall process of health promotion 'which encompasses actions to protect or enhance health, including legal, fiscal, educational and social measures' but that education for health is a crucial component 'to lay the foundations before other components can come into play'. 4

The criticisms of health education described earlier relate specifically to the traditional 'preventive' model, in which people are persuaded to adopt healthy lifestyles. But, in addition to individual decision making, education can also be directed at professionals, at lobbying and advocacy, at changing the political agenda, and at general awareness. Which models of health education encompass these?

Tones and Tilford characterise the different philosophies, ideologies, and values of three broad models of health education as 'preventive', 'radical', or 'empowerment' models. ${ }^{5}$ It is beyond the scope of this review to discuss these models in detail, but a brief summary follows to demonstrate the breadth of approaches available within a health education framework.

(1) The preventive model is an individually focused and medically dominated form of health education. It tends to be politically and ideologically favoured in an era of individualised culture. It provides people with information on which they are expected to act, assuming individual responsibility for their own health. This model seeks approved behavioural outcomes and has been criticised because of its tendency to blame the victim.

(2) The radical model, in contrast, is more collectivist in outlook. It is an environmental 'upstream' model that challenges the view that the individual is to blame for his/her own health. It stresses social and environmental, rather than individual factors. It seeks social change rather than individual change and is involved in critical consciousness raising, breaking free of uncritical acceptance of causality.

(3) Within empowerment models, process is more important than outcomes. Value is placed on 'voluntarism', in which the learner must understand the process by which he or she is learning. It enhances self esteem and a willingness to take control. ${ }^{5}$ 
These three models stem from different ideologies and philosophies of society that initially seem to be diametrically opposed. In practice, however, there are a number of overlaps. ${ }^{5}$ Each model could also give rise to different educational methods: the preventive to a more didactic style of presentation, the radical and empowerment models to more exploratory learning methods. But again, an overlap can occur between these methods.

\section{What are the principles of education that facilitate effective teaching and learning?}

Modern educational theory emphasises the learning of processes and minimises the learning of facts. ${ }^{6}$ Minds are not empty vessels to be filled with facts. Education needs to be carefully structured to take individuals and groups through the learning process in an effective and motivating way. Educators need to build from the known to the unknown; from the simple to the complex. Learning is more effective when it is organised in a spiral in which issues are revisited in increasing depth as time goes on, rather than in a linear series of 'one off' experiences. ${ }^{7}$ People learn best when experiences are brought together and reinforce one another - when topics are not tackled in isolation but used in a coordinated manner, and when different learning experiences complement each other. When people engage actively in the learning process they are more likely to be influenced by it.

The educational task needs to be right for the learner: it needs to take into account the learner's stage of development. It should also start from where people are emotionally and be concerned with self esteem and relationship skills. The social context of the learner - their social background, for example - can have a profound effect on their response to education.

These educational principles can be applied both to individuals, whether they are parents, children, policy makers, to groups of professionals, or the public.

\section{Available strategies for different injury types} Unintentional injury is not homogenous. Childhood injuries occur in the home, road, and leisure environments and encompass a wide range of causes and possible countermeasures. ${ }^{89}$ For some injury types, a wide range of countermeasures are possible, though not always put into action. Pedestrian injuries, for example, can potentially be prevented through a range of techniques, including traffic calming measures, changes in land use, transport policies, provision of school crossing patrols, speed restrictions, and also through educational programmes directed at the child, or car driver. For other injuries, such as drownings in the bath tub, 'passive' environmental or legislative approaches are not possible and educational/training approaches are the only ones available.

Just concentrating on those injury types for which there are 'proved', effective environ- mental or legislative interventions means that other areas may be neglected.

\section{Educational programmes: characteristics of unsuccessful and successful programmes}

Over the years, there have been a number of educational interventions directed at behaviour change in parents and children. What are the characteristics of those campaigns that are most successful and those that are not succesful?

Examples of campaigns that have not proved to be effective include those reported by Minchom et al, ${ }^{10}$ Dershewitz et al, ${ }^{11}$ Schlesinger et $a l,{ }^{12}$ and McLoughlin et al. ${ }^{13}$ In a home safety campaign in Cardiff directed at parents, no significant improvement in injury rates could be detected. However the campaign was short, it was traditional in style, comprising leaflets, posters, speakers at local organisations, and one off sessions in schools. Penetration levels were relatively low, and baseline and follow up data collected over a short period. ${ }^{10}$

A community wide home safety campaign directed at parents of young children in Rockland County in the US, showed no significant gains in terms of reduced injury rates. ${ }^{12}$ The programme involved neighbourhood discussion groups and identified hazards and preventive methods appropriate for each age group. Pless and Arsenault considered these educational techniques to be 'state of the art' and penetration to the population was high and they consequently believe that the conclusions from this study are sobering in relation to health education. ${ }^{14}$ In both this and a later campaign, ${ }^{11}$ however, which involved personalised advice and provision of free home safety devices, the range of messages was great. This led the authors to conclude that household injury control was too broad a field for health education to be effective.

Project Burn Prevention, a large campaign conducted in the US by McLoughlin et al,,$^{13}$ reported knowledge gains but no reduction in burn injuries or severity in the long term. The authors provide a very useful critique of the study. They feel the programme 'addressed too many topics for persistent learning about any topic to occur, or for learning to motivate changes in behaviour related to burn prevention'. ${ }^{13}$ Moreover, the duration of the programme may not have been long enough for persistent learning to take place. An important issue also raised was that 'demonstration projects awarded by competitive process and funded by contracts to accomplish an objective of a Federal agency, will rarely have as a major goal to meet the express primary needs of the community'. ${ }^{13}$ Here, the community was the site, not the source, of the programme.

In these studies where educational interventions were not effective: the nature of the programme may not have been suited to the target group; the number of messages too great; the duration too short; or the source of the programme inappropriate.

Turning to campaigns where some successes have been achieved, one home safety campaign 
attempted to address two of the above issues (namely advice that was often inappropriate and too diffuse). ${ }^{15}$ This campaign was conducted in a disadvantaged community in Newcastle, England; it compared the effects of a mass media campaign, the BBC Play it Safe series, with a mass media campaign combined with targeted advice by health visitors during planned home visits using home safety knowledge and actions of families as end points. Nine per cent of the first of these groups of families (the control group) made some physical changes to make their homes safer, compared with $60 \%$ of the second (the intervention group). The authors of the study believe that the advice given was small, specific, and concrete: the severely disadvantaged families responded because the education was appropriate to their immediate needs. ${ }^{15}$

In the road safety field, difficulties can also arise because of the complexity of the education and training tasks. Rivara et al have estimated that road crossing can involve up to 26 different tasks to negotiate traffic. ${ }^{16}$ Some training programmes targeted on clearly defined road crossing skills have, however, been demonstrated to be effective. Thomson et al in Glasgow, Scotland have developed programmes to train young children to find safe places to cross the road. ${ }^{17}$ There is a need, however, for small scale experimental studies such as these to be extended into wider operational programmes where parents can help to transmit the skills. These studies are continuing in Glasgow.

An example of a small scale behavioural programme developed into a larger scale version comes from the US: Roberts et al used behavioural procedures, involving rewards, modelling, prompting, and feedback in two schools in an experimental programme expanded to a larger operational programme in 25 schools. ${ }^{18}$ What was important in this study was the use of rewards (stickers, car bumper strips, and prizes of pizza dinners): over $60 \%$ of children wore seatbelts compared with $18 \%$ before the programme and when these incentives were withdrawn, the compliance declined to $49 \%$. The authors felt that 'basic information and publicity on passenger safety are helpful, but inefficient to achieve great impact on behaviour. The clear and dramatic effect of rewards lend credence to the use of incentives to motivate safety behaviour'.18 Peterson believes that 'feedback, rewards and behavioural rehearsal are extremely important to the success of educational programmes and are to be preferred to didactic and passive measures'. ${ }^{19}$

It has been possible to demonstrate effectiveness in single measure interventions, such as increasing seat belt use or bicycle helmets, within 'closed' systems such as schools. A bicycle helmet campaign in Seattle in the US, included the main ingredients that characterised the most successful interventions. ${ }^{20}$ The age group of this campaign was narrow, the campaign had a single aim (increasing helmet wearing rates), and the educational methods employed, which ranged from mass media to targeted one to one counselling, reinforced one another. The campaign also addressed the issue of cost of helmets by a variety of subsidies.

Many successful campaigns, in addition to having an educational component, increase use of a particular item of safety equipment by improving its availability and reducing its cost. An often quoted study is the Children can't fly campaign in New York, where a variety of approaches were adopted including a mass media campaign, individual education, and home inspection. ${ }^{21} \mathrm{~A}$ key factor was that free window bars were provided, and in many cases, fitted, where children were at risk. The authors reported a $50 \%$ decline in falls from windows in the Bronx area, $31 \%$ city wide, and a 35\% decline in mortality due to these falls. Success can be greatest when a combination of approaches: educational and environmental are adopted.

In addition, there are other possibly fruitful area of research. These include improving driver behaviour, which 'has never been an areas of emphasis either in Europe or in the United States'. ${ }^{22}$ In Nottingham, England, Thompson et al measured vehicle speeds outside junior schools and the distance between the car and the kerb. ${ }^{23}$ Drivers' speed and position in the road were unaffected by the presence of children by the roadside. Even large groups of child pedestrians had the effect of reducing mean speeds by only one mile an hour. Vehicle drivers were not prepared for the unpredictable behaviour of child pedestrians. Howarth believes that 'pedestrian safety could be most effectively increased by measures aimed at increasing the responsibility of drivers for avoiding more accidents'. ${ }^{24}$

The more widespread use of behavioural methods involving rewards and behavioural rehearsal could be considered ${ }^{18} 19$ as could the use of methods such as 'children helping children', 25 and 'community mothers' ${ }^{\text {'26 }}$ which have been applied in other areas of health education.

\section{The role of education in legislation}

It has often been stressed that legislation is an effective solution in injury prevention. But it depends on whether the legislated action is a single, one off event that offers passive protection to the vulnerable recipient or whether it requires repetitive action. Examples of the former include product design, such as the redesign of front loading washing machines to avoid chest scalds in young children, ${ }^{27}$ or redesign of products associated with suffocation and strangulation-such as refrigerators, infant cribs, and plastic bags. ${ }^{28}$ Examples of legislation that require repetitive action include bicycle helmet wearing, seatbelt wearing, and the use of infant car safety seats. Intermediate between the two of these are child resistant containers to prevent poisonings and fencing for domestic swimming pools. Both offer a degree of passive protection when used correctly (putting the lids back on containers and closing the gates of the swimming pool fences).

Education has a role in the process of imple- 
menting legislation by influencing policy makers and changing public opinions. Legislation can happen overnight, but usually takes a long time to achieve: Pearn notes that 'it took 22 years after the discovery of poisoning by leadcontaining paints before Queensland was reluctantly dragged to the point of introducing safety legislation which would protect children' ${ }^{29}$ What is involved is a process of trying to get people to believe that there is a problem, that it is a higher priority, that it is possible to do something about it, and that legislation would be effective.

The process of implementing legislation can be illustrated by Katcher's experience in Wisconsin, USA, in implementing a programme to prevent tapwater scald injuries reported in National Committee for Injury Prevention and Control $1989 .^{30}$ Having established by local studies that a problem and solution existed, Katcher believed at the outset that the most effective intervention was state or national regulations requiring manufacturers to set all new water heaters at a maximum temperature of $120-130^{\circ} \mathrm{F}$. Initially however there was little support for such regulations in Wisconsin or at federal level. From 1982-5, Katcher focused on educational interventions, targeting medical professionals to convey the message of educating parents about the dangers of excessive hot water. Katcher's 1985 efforts to initiate state legislation failed, but over the next two years a strong lobbying group of medical and nursing professionals and state legislators persuaded the Assembly and Senate to pass the Bill in 1987. Similar laws were then passed in Florida and Washington. This was then used to approach water heater industry leaders to urge the adoption of voluntary standards. Within this process, Katcher concentrated on activities in areas where success was most likely: education campaigns directed at professionals and parents when the political climate would not suppport a legislative intervention, advocacy to enable passage of the water heater law, and the Wisconsin legislation as leverage for national voluntary standards. ${ }^{30}$

Stone, in his critique of health education, states that 'thousands of lives were lost during the years of fruitless political lobbying before seatbelt wearing was made compulsory'. ${ }^{1}$ In the UK, the first parliamentary questions relating to mandatory front seat belts in cars was raised in 1959. The first formal proposal was made in 1973, but legislation was not approved until $1981 .^{31}$ This period of 22 years did not represent 'fruitless lobbying' but a slow and difficult process of understanding what the issue was and overcoming objections, such as loss of personal freedom. Legislation does not take place in a vacuum divorced from any learning process. Factors contributing to the success of this measure included the support of professional groups, police, medical, community and academics (all taking time). These groups were able to gain considerable attention from the media in a campaign to bring the issue to parliament. A television documentary The greatest epidemic of our time viewed by half the population of the country, was shown a week before the vote in parliament and had a powerful effect. ${ }^{31}$

Education is important in influencing the development of policy and resulting legislation, by influencing public opinion before such legislation and in maintaining compliance with legislation when passed. Before bicycle helmet legislation came into effect in Victoria, Australia in 1990, there had been a 10 year campaign to promote helmet use through bicycle helmet promotion in schools, mass media publicity, support by professional organisations and community groups, bulk purchase schemes, and government rebates for helmet purchases. In Melbourne, there had been a steady increase in voluntary helmet use from 1983-90$5 \%-70 \%$ in primary schoolchildren and $2 \%-20 \%$ in secondary school pupils. After legislation, these rates increased to $70-90 \%{ }^{32}$ 'The strategies and activities necessary to achieve the ultimate goal were multi-faceted and involved support from a wide range of community and professional organisations'. It is important in seeking the introduction of similar measures to recognise the need for such a widely based approach and the need for patience and perseverance.

Proponents of political intervention seem to assume that the introduction of legislation is all that is needed, but for this to be effective in practice requires a high level of acceptance and appreciation of the value of the legislation: this therefore includes some form of education. In the US, all states have laws requiring that young children be restrained in cars, but Wilson and Shock report that 'observational studies show that about one fifth of infant passengers still ride unrestricted on the lap of another occupant'.$^{33}$ Maintaining a climate of opinion in which child safety seats are deemed important, and reminding parents of the continued need for using these seats, as well as using them correctly, requires continued mass media and individual education campaigns. Political culture has an important impact on public acceptance of policy choices. After legislation, seat belt usage in Britain has been around $95 \%$ whereas in the US, seat belt usage has been much lower and there are considerable variations between states. Leichter argues that British political culture has historically been more deferential than the more individualistic culture of the US. ${ }^{31}$

Sociopolitical climates do not stay still. In Britain and elsewhere in Europe, there is a political will that favours the relaxation of regulations and legislative controls on business activities, and these have included a range of safety measures. A continued process of education is required to persuade decision makers about the effectiveness of measures and to retain the political will to sustain legislation.

\section{The role of health education in} environmental change

Critics of health education suggest that environmental changes are more significant in preventing injury, but what has been the process by which large scale environmental 
measures, such as area wide urban safety schemes to reduce road traffic accidents, have been introduced? Dissemination of scientific reports among professional groups, lobbying of decision makers, initiation of experimental studies, and wider application of effective measures are all parts of the process. Large scale demonstration studies are expensive and time consuming: the Transport and Road Research Laboratory in Britain set up the Urban Safety Project to evaluate urban safety schemes in five towns in England. ${ }^{34}$ Each scheme cost $£ 250000$ and the project took place over seven years. The $13 \%$ reduction in accidents resulting from the scheme led to a national strategy for urban safety management. Ward points out, however, that local area safety schemes only work effectively if local people have been involved in setting the agenda for the schemes. ${ }^{35}$ The sophistication of the engineering measures was not matched by the consultation process with the public. Consultation often resulted in safety considerations being compromised in favour of access. Greater local acceptance of schemes might have been achieved by greater public consultation and use of the media to explain the benefits these schemes would bring to local populations and perhaps even greater reductions in accidents might have occurred. ${ }^{9}$

\section{Education of professionals, policy makers, and the wider community} The issues discussed so far in this paper have brought into focus the importance of educating professionals to prepare them for their role in education for health and to alert them to the wider social issues of making the environment safer. In the UK health visitors are the only professionals who have long term regular contact with families from soon after the birth of a child. The Newcastle study, referred to earlier, of health visitor home visits demonstrated their effectiveness in influencing families to improve the safety of their homes. But there are many competing demands on health visitors' time. In addition, Laidman found that when she studied the role of health visitors in injury prevention, their knowledge was 'little better than the public they serve' and she identified a number of communication problems. ${ }^{36} \mathrm{~A}$ training resource for health visitors was subsequently developed to address the issues raised. This stressed not only work with individual families, but also work at a community level, supporting local groups in campaigns for safer environments. ${ }^{37}$ This training resource has been widely used and disseminated, but unfortunately no funds have been allocated to evaluate its impact at a local level.

In the study of Corkerhill, Glasgow referred to earlier, Roberts et al contrast the preventive ambitions for safety of health professionals working in the area and citizens' groups living in the area. ${ }^{2}$ The citizens' groups focused on housing, whereas the professionals were more modest and focused solidly on education: 'we have to educate them, the parents, that the home is really the most unsafe place you can be'. ${ }^{2}$ The educational tasks here would include widening the professionals' horizons about different strategies of injury prevention, increasing their skills in local advocacy work, and learning about citizens' conceptions of need in their area.

The community wide programme of injury prevention in Falköping, Sweden prioritised the education of policy makers and health workers. ${ }^{38}$ Results of an injury surveillance system were used to stimulate local interest in the programme from professionals and the public alike. 'Local injury data are necessary to gain the support of local authority organisations and the population, who may not believe that the problem exists in their community'. ${ }^{38}$ The Falköping programme also relied on a reference group or 'healthy alliance' drawn from a wide range of health, local authority, voluntary, and community agencies to coordinate and plan the prevention activities. This model of community based programmes has become the basis for the WHO's Safe Communities programme, ${ }^{39}$ and has also been adopted in a number of other areas such as the Ilawarra area of New South Wales, ${ }^{40}$ and the Safe Kids Healthy Neighbourhood injury prevention programme in Harlem. ${ }^{41}$

Involving the community through the media was well demonstrated by Schelp in Falköping, Sweden where local journalists were involved in the planning group. ${ }^{38}$ Safety promoting messages need to be introduced into how the media report on injury 'which often dwells on bizarre or gruesome aspects of individual cases' ${ }^{42}$ In reporting on individual cases, 'what is missing is the depiction of injuries as understandable, predictable and in many cases preventable, events' ${ }^{30}$ Resulting for this is 'the vast majority of legislators, governors, commissioners, physicians, nurses, lawyers and the general public [who] continue to view injuries of acts of fate'. ${ }^{30}$

Lescohier points to an expansion of the role of education to alter the public perception of risk in order to change social norms, for example, in relation to drinking and driving. The work of grass roots organisations, such as Mothers Against Drunk Driving (MADD) has received a great deal of media attention and helped to influence local communities. ${ }^{42}$

Both 'top down' and 'bottom up' approaches can help alter social norms in relation to safety. In the work in Corkerhill, Glasgow with citizens' groups, parents already exercised a range of preventive actions. There is a need to consult those whose day to day lives are a reservoir of effective safe keeping strategies and use this in education as appropriate. ${ }^{2}$

\section{Conclusion}

Whitehead, in surveying the wider scene of health education, has concluded that most of the activity has been concerned with individual lifestyles and that 'there has been a neglect of education concerned with social and environmental influences on health and a relative neglect of education directed at local and national policy makers as opposed to the 
general public'. ${ }^{4}$ This can be echoed in the field of injury prevention and safety promotion. What this article has sought to illuminate is this broader definition of health education and its importance in injury prevention, as a foundation for both environmental change and legislation.

There are still many gaps in our knowledge of how best to influence policy makers, professionals, children, parents, and the wider community. Very few evaluated studies of interventions pay any attention to measuring process. It is important to be able to identify successful and unsuccessful components of campaigns and understand why a programme works in specific circumstances or localities and not in others. Only then can we transport those effective components to other areas and to learn from earlier mistakes. There has been a false distinction between the role of health education, environmental measures, and legislation: in practice the three are interlinked and their synergistic effect is important. The challenge is to make the educational process more effective in all the contexts in which it takes place.

1 Stone D. Upside down prevention. Health Service fournal 1989; 99: 890-1.

2 Roberts H, Smith S, Bryce C. Prevention is better . . . Sociology of Health and Illness 1993; 15: 447-63.

3 Sibert JR. Accidents to children: the doctor's role. Education or environmental change. Arch Dis Child 1991; 66: $890-3$.

4 Whitehead M. Swimming upstream: trends and prospects in education for health.London: King's Fund Institute, 1989.

5 Tones K, Tilford S. Health education. Effectiveness, efficiency and equity. 2nd Ed. London: Chapman and Hall, 1994.

6 Weare $\mathrm{K}$. The contribution of education to health promotion. In: Bunton R, Macdonald G, eds. Health promotion disciplines and diversity. London: Routledge, 1992: disciplines

7 Bruner J. Towards a theory of instruction. Cambridge: Harvard University Press, 1966.

8 Pless I. The science and art of injury prevention in childhood: perspectives from Britain and abroad. London: Child Accident Prevention Trust, 1992.

9 Towner E, Dowswell T, Jarvis S. Reducing childhood accidents. The effectiveness of health promotion interventions: a literature review. London: Health Education Authority, 1993.

10 Minchom P, Sibert J, Newcombe R, Bowley M. Does health education prevent childhood accidents: Postgrad Med $\mathcal{F}$ 1984; 60: 260-2.

11 Dershewitz $R$, Williamson J. Prevention of childhood household injuries: a controlled clinical trial. Am $\mathcal{f}$ Public household injuries: a cont

12 Schlesinger E, Dickson D, Westaby J. Lowen L, Logrillo V, Maiwald A. A controlled study of health education in aaiwald A. A controlled study of health education in accident prevention. The Rockland County

13 McLoughlin E, Vince C, Lee A, Crawford J. Project burn prevention: outcome and implications. Am $\mathcal{F}$ Public Health 1982; 72: 241-7.

14 Pless I, Arsenault L. The role of health education in the prevention of injuries to children. Fournal of Social Issues 1987; 43: 87-103.

15 Colver A, Hutchinson P, Judson E. Promoting children's home safety. $B M \mathcal{F} 1982 ; 285$ : 1177-80.
16 Rivara F, Booth C, Bergman A, Rogers L, Weiss J Prevention of pedestrian injuries to children: effectiveness of a school training program. Pediatrics 1991; 88: $770-5$

17 Thomson J, Ampofo-Boateng K, Pitcairn T, Grieve R, Lee $\mathrm{D}$, Demetre J. Behavioural group training of children to find safe routes to cross the road. Br $¥$ Educ Psychol 1992, 62: 173-83.

18 Roberts M, Fanurik D, Wilson D. A community program to reward children's use of seat belts. Am $\mathcal{f}$ Community Psychol 1988; 16: 395-407.

19 Peterson L. Preventing the leading killer of children: the role of the school psychologist in injury prevention. School of the school psychologist in injury pre

20 Bergman A, Rivara F, Richards D, Rogers L. The Seattle children's bicycle helmet campaign. Am $\mathcal{F}$ Dis Child 1990, 144: 727-31.

21 Spiegel C, Lindaman F. Children can't fly: a program to prevent childhood morbidity and mortality from window falls. Am F Public Health 1977; 67: 1143-7.

22 Malek M, Guyer B, Lescohier I. The epidemiology and prevention of child pedestrian injury. Accic Anal Prev 1990; 22: 301-13

23 Thompson J, Fraser E, Howarth C. Driver behaviour in the presence of child and adult pedestrians. Ergonomics 1985; 28: 1469-74.

24 Howarth I. Interactions between drivers and pedestrians: some new approaches to pedestrian safety. In: Evans $L$, Schwing R, eds. Human behaviour and traffic safety. New York: Plenum Press, 1985: 171-82.

25 Morgan M, Shute R. Smoking education and peer group influence. In: Foot $\mathrm{H}$, Morgan M, Shute R. eds. Children influence. In: Foot H, Morgan M, Shute R. eds. Children

26 Johnson Z, Howell F, Molloy B. Community mothers' programme: randomised controlled trial of nonprofessional intervention in parenting. $B M \mathcal{F} 1993 ; 306$ 1449-52.

27 Sorenson B. Prevention of burns and scalds in a developed country. Trauma 1976; 16: 249-58.

28 Kraus J. Effectiveness of measures to prevent unintentional deaths of infants and children from suffocation and strangulation. Public Health Rep 1985; 100: 231-40.

29 Pearn J. Safety legislation and child mortality. [Leading article]. Med f Aust 1991; 154: 155-6.

30 National Committee for Injury Prevention and Control. Injury prevention: meeting the challenge. New York: Oxford University Press, 1989.

31 Leichter H. Free to be foolish. Politics and health promotion in the United States and Great Britain. Princeton, NJ: the United States and Great Britai

32 Vulcan A, Cameron M, Watson W. Mandatory bicycle helmet use: experience in Victoria, Australia. World $\mathcal{f}$ Surg 1992; 16: 389-97.

33 Wilson M, Shock S. Preventing motor vehicle-occupant and pedestrian injuries in children and adolescents. Current Opinion in Pediatrics 1993; 5: 284-8.

34 Mackie A, Ward H, Walker R. Urban safety project 3. Overall evaluation of area wide schemes. Crowthorne: Tranport and Road Research Laboratory, 1990. (Research report RR 263.)

35 Ward H. Prevention road accidents to children. The role of the NHS. London: Health Education Authority, 1991.

36 Laidman $\mathrm{P}$. Health visiting and preventing accidents to children. London: Health Education Authority, 1987.

37 Health Education Authority. Preventing accidents to children. A training resource for health visitors. London: Health ren. A training resource for health
Education Authority, 1991.

$38 \mathrm{Schelp} \mathrm{L}$. The role of organizations in community participation - prevention of accidental injuries in a rural Swedish tion - prevention of accidental injuries in a rural
municipality. Soc Sci Med 1988; 26: 1087-93.

39 Karolinska Institute Department of Social Medicine. Report of second travelling seminar on safe communities. Sundyberg, Sweden: Karolinska Institute, 1991

40 Jeffs D, Booth D, Calvert D. Local injury information, community participation and injury reduction. Aust $\mathcal{f}$ Public Health 1993; 17: 365-72.

41 Davidson L, Durkin M, Kuhn L, O'Connor P, Barlow B, Heagarty $M$. The impact of the safe kids/healthy neighborhoods injury prevention program in Harlem, 1988 through 1991. Am ₹ Public Health 1994; 84: 580-6.

42 Lescohier I, Gallagher S, Guyer B. Not by accident. Issues in Science and Technology 1990; VI(4): 35-42. 